\begin{tabular}{c} 
EPiC Series in Education Science \\
Volume 1, 2017, Pages 147-155 \\
$\begin{array}{l}\text { AUBEA 2017: Australasian Universities Build- } \\
\text { ing Education Association Conference 2017 }\end{array}$ \\
\hline Science
\end{tabular}

\title{
Use of Timber Prefab System for Ensuring Sustainable Residential Housing Supply in New Zealand
}

\author{
R. Ansari ${ }^{*}$, T. Egbelakin ${ }^{2}$ J. Mbachu ${ }^{3}$ \\ Massey University, Auckland, New Zealand \\ R.Ansari@massey.ac.nz, T.Egbelakin@massey.ac.nz, \\ J.I.Mbachu@massey.ac.nz
}

\begin{abstract}
New Zealand housing shortage requires effective approaches to address the increasing demand over the next twenty years. Given the current situation of the New Zealand's housing crisis, it is almost impossible to meet that demand by using the traditional methods of construction. Offsite manufacturing system can help improve housing supply capability in New Zealand. With timber being a very sustainable resource and abundant in New Zealand, timber prefab system offers the most economically and environmentally feasible solution to the housing supply challenges in New Zealand. This research aims to investigate a method that New Zealand construction industry can adopt in the offsite manufacturing system at a national scale to improve the residential housing crisis. Ten interviews and ten questionnaires were conducted with clients, designers, prefabricators, and suppliers to identify the risks and required actions in order to achieve successful application of the system. The impacts of several factors on the system such as barriers, enablers and sustainability aspects of using the timber prefab system were studied as part the research objectives. The results reveal the most sustainable method of residential housing supply in the New Zealand within the acceptable risks, productivity and having a secure government investment support.
\end{abstract}

\section{Introduction}

The poor standard of current housing and the inability of too many people on low incomes to access decent housing is causing a group of problems that are avoidable (Howden-Chapman, 2015). Today there is a crisis, not only in access to and affordability of housing in New Zealand, but in the quality of the housing (Howden-Chapman, 2015). An estimated 91\% of Greater Christchurch dwellings suffered 
some type of damage, in which approximately $7.5 \%$ of buildings collapsed or required demolition (Dionisio et al., 2016). The New Zealand construction industry council mission is to work effectively within the design and construction industry, specifically between regulators and industry stakeholders, to continuously improve efficiency, resilience, quality and professionalism. The New Zealand government started a BIM acceleration committee, as part of a productivity partnership with the goal of 20 per cent more efficiency in the construction industry by 2020 . Adding the prefabrication industry to the BIM may cause the significance and positive result in the New Zealand's residential housing industry. Also, modular construction as one of the offsite manufacturing methods can save around half of construction time compared with traditional construction (Mah, 2011, Lawson and Ogden, 2010, Smith, 2011).

Numerous benefits that prefab can offer have been researched in several studies (Te Roopu Taurima, 2016). For example, workers in the factory use lasers to cut the wood and jigs to place the pieces together, the quality is very consistent. The workers are also very efficient because they do the same job repeatedly, which increases their skills and reduces errors. Very little waste is created and no materials are damaged by moisture, which creates a home with very good indoor air quality that is far superior to the average stick-built home knowing the price of a project upfront is important, modular construction can offer far more precision. Therefore, this is especially helpful when building rental properties because an accurate estimate for return on investment can be easily calculated. Knowing the price upfront also benefits investors in that they can know exactly how long it will take to get a return (Te Roopu Taurima, 2016). There are some challenges in the New Zealand prefabricated systems such as project planning, transportation restriction, negative perceptions, high initial cost, coordinate and communication in the modular housing systems (Conducted interviews).

Few studies have looked at the sustainable timber prefab system to improve the housing crisis in NZ. This research contributes to filling this knowledge gap by seeking and analyzing the appropriate benefits and challenges of the prefab system. That may support processes of community and stakeholder engagement and decision-making, to achieve better residential redevelopment outcomes at the wide scale.

\section{Literature Review}

\subsection{Residential housing}

The New Zealand residential industry is in an ideal position to benefit from decades of overseas experience and adopt the knowledge and technique to suit the local context. There is significant scope for New Zealand's residential construction industry to create aspirational industry quality standards or label to enable the customer to better understand the quality of what they are buying (Buckett et al., 2007). The majority of the new housing in New Zealand is detached housing (Page, 2013).

There is a significant concern over the shortfall between increasing population in many of the main urban centers in New Zealand and the rate of construction of the new dwellings. Auckland is particularly hard hit, with around a third of New Zealand's population (QuickStats, 2013). Christchurch has housing pressures relating to a decrease in housing stock and a sudden increase in population (Business, 2013). In Auckland in particular the inflation of house prices and rent has become a major concern (Buckett et al., 2007). The average firm size is likely to increase, which will lead to a significant change in the characteristics of new housing, possibly leading to better quality, enhanced affordability and improved sustainability (Page, 2013). 


\subsection{Why timber in the residential housing?}

As a results of (Ede et al., 2015) concrete is stronger and heavier than timber. The lighter weight of timber structure entails a smaller foundation and therefore economic advantage. The lighter weight of timber is of a particular advantage where sub-soil conditions are poor and prone to differential movements. From the cost point of view, the timber model has a better advantage to the concrete as it appears more economical (Ede et al., 2015). On environmental impact and energy efficiency analysis, timber made buildings are more environmentally friendly compared to concrete structures. Therefore, (Ede et al., 2015) proved beyond reasonable doubt that timber is an excellent material for residential buildings and moderate size buildings in comparison to concrete.

Maximizing the use of timber in future urban developments demonstrated that Auckland's target of a $40 \%$ carbon emissions reduction by 2040 could be achieved $20 \%$ faster than planned while still meeting the city's future growth needs. This strategy is complementary to, and easy to integrate with, other strategies and policies for greenhouse gas mitigation (Stocchero et al., 2017). In addition, new forms of pre-stressed timber construction being developed at the University of Canterbury have the potential to revolutionize large scale timber buildings. The new technology can be used for multi-story timber buildings up to 10 stories (Buchanan et al., 2008).

In summary, taking the viewpoint of a consumer, three typical houses compared in which steel, concrete or wood is the dominant component. It appears that wood, wood components, and houses built primarily of wood require lesser amounts of energy in their manufacture, assembly, and operation.

\subsection{Type of prefabrications}

(1) Component-based prefabrication includes stick and sub-assembly prefabrication. Stick refers to lengths of timber or steel that are pre-cut, pre-sized or pre-shaped puzzle-type pieces brought to site where they are assembled by a builder, as opposed to the traditional construction process which cuts timber to size at site (Bell, 2009). (2) Panelized or non-volumetric prefabrication comprises manufactured panels that may include integrated building services. While panelized elements can be stacked flat for efficient transportation to site, they require more work for assembly at site than modular units. (3) Modular offers designers and architects flexibility which is cost-effective (CIMC, 2017). Interviewee 5: Modular technology considerably reduces construction time. It is safer, quieter and cleaner than traditional. Modules are fully fitted out inside, in a controlled factory environment, which results in a high level of quality and repeatability, and leads to significant construction program benefits. In addition, compared to traditional construction, modular construction time can be reduced by $30 \%$ $60 \%$. On-site labor is typically reduced by $70 \%$ which leads to considerable benefits on site for access, storage of materials and Health \& Safety issues in general (CIMC, 2017). Therefore, modular building allows reductions in the overall capital costs by $10 \%-30 \%$, through greater efficiencies of design, delivery and onsite management. (4) Hybrid systems use "volumetric units for the highly serviced areas such as kitchens and bathrooms and construct the remainder of the building using panels or by another means". (5) Complete buildings are commonly known as portable, relocatable or transportable dwellings in New Zealand and they are a type of volumetric prefabrication where entire buildings are constructed in a factory or yard and then moved to site where they are attached to permanent foundations.

\subsection{Benefits of the prefabrication compared to conventional housing system}

The merits of prefabrication are potentials, rather than givens, as each individual example of prefabricated housing possesses its own particular systems and processes (Interviewee 4). Prefabrication can potentially offer 'more for less': more quality for less time at site, more known 
outcomes and less unknowns, and potentially more energy efficiency for less resource use (Interviewee 2). Prefab system is a construction technique in which a building's components are manufactured in a controlled environment (on- or off-site), transported, positioned, and assembled into a structure; only minimal additional work is done on-site (Interviewee 1). Prefabrication is a process of social and economic change whereby a human society is transformed from a preindustrial to an industrial state (Mohd Nawi et al., 2011). It is a part of wider modernization process through the technology system and one of the solutions for this increasing housing demand. Prefab system improves the quality of projects, easier to control, reducing rectification work and lowering the total cost of construction (interviewee 6). Building production in a controlled environment offers many advantages such as minimizing construction time, increasing the quality of buildings, reducing construction cost, enhancing occupational health and safety, and reducing construction waste (Interviewee 7).

A strong emphasis of sustainability needs to be demonstrated through built environment planning, design and construction economics (Mohammad, 2013). The choice of using the prefabricated system in a sustainable commercial development is expected to enhance the quality of life and work for today and future generation. Quality, speed of construction, and cost savings are the main advantages of these systems (Interviewee 3). The expansion of industrialized construction and prefabrication in a controlled environment has allowed issues of sustainability to be addressed more quickly and efficiently (Umair et al., 2015, Nadim and Goulding, 2010).

In summary, the application of prefabricated systems has been encouraged as a means of providing better quality products in a shorter amount of time and reducing both labor and material costs.

\subsection{Merits of the prefabricated systems}

The merits of prefabrication are established, yet traditional housing methods dominate the construction industry.

Sustainability merits and challenges, in particular, infrastructures have major influence on the attainment of sustainable development, thus project sustainability needs to be considered (Shen et al., 2010). Material usage is thought to be saved by up to seventy-five percent for modular construction (Bell, 2009). Currently forty percent of our country's waste is created by the New Zealand construction industry so there could be great improvements made in the area of waste minimization (Wood, 2008). Potential site benefits of prefabrication include less disruption, noise, pollution, effluence, groundworks, traffic, and fewer deliveries. Environmentally, for every $1 \%$ increase in the proportion of prefabricated components, CO2 emissions decreased approximately 45,505 (kg-CO2) (Mao et al., 2013).

Social merits include being able to work under cover during inclement weather, having tools and amenities close at hand, and improvements in health and safety (Interviewee 2). Economic merits include the cost savings to customers and developers from a shorter period of financial borrowing as a result of shorter timeframes, and reduced defect liability periods (Interviewee 10). Timeframes and costs will also be decreased by eliminating dependence on weather for site-based construction, easier coordination of trades in-house, and price advantages from bulk ordering.

In conclusion, to take timber housing from the level of unique experimental projects to competitive industrialized production, manufacturers will have to face the challenge of convincing the market that timber is an equally sufficient material as the more traditional concrete and steel.

\section{Scope of the Study}

The research focus is to develop the innovative approaches and strategies that NZ construction industry can adopt a national scale to improve the housing crisis. Therefore, The research would be conducted from mainly of the master builders, PrefabNZ, prefabricated builder, and BRANZ 
associations. Those are necessary as they are some experts that can influence on the NZ's housing crisis. Therefore, it is appropriate in this research to use these people as the unit of analysis in the study.

During the period of 2006 to 2031, the predicted new demand for housing in Auckland may exceed the predicted delivery of new housing by nearly 120,000 (Burgess et al., 2013). Therefore, Auckland was selected as a geographical coverage area for obtaining research information and based on the current number of the housing shortages.

\section{Research Method}

The use of multiple sources of data and methods, assist to confirm the emerging findings and ensure that data reliability and internal validity is strengthened (Marriam,1998).

\subsection{Data gathering}

The qualitative and quantitative data collection methods adopted in this study are face to face interviews and distributing the questionnaire survey among the experts. The plan and structure for data collection methods used in this research was designed to ensure that information could be systematically gathered and synthesized across the Auckland.

A personal face-to-face interview was adopted as the data collection technique for the qualitative research phase because it allows an in-depth understanding of the research topic, its relevance to the experts such as NZBuilders, PrefabNZ, and BRANZ members and the prefabricated construction companies to gain more insights into the research problem. The interviews took place in the interviewee's respective offices within the different locations. Ten out of the fifteen companies accepted the invitations for interview, which provided them 14 open-ended questions, pertaining to the current NZ's construction industry and challenges.

After qualitative date collection and based on the formulation of the AHP method for weight assigning, a questionnaire survey was conducted to collect data from selected experts for analyzing the significance of one factor in comparison to the other ones. For this purpose, 10 professionals from the construction industry sectors were invited to compare and assign relative weights to indicate the significance of pairs of factors by using the pairwise comparison.

\subsection{Data analyzing}

Data from the face to face interviews were reviewed to find out the barriers and enablers. Then the AHP method utilized to rate enablers and the sustainability ratio of each prefab methods.

The AHP method was developed by Thomas Saaty (Saaty, 1980), and has been extensively studied and refined since then (Zhang and Zou, 2007). The adoption of the AHP method in this step led to generating the matrixes for comparing different factors. Finally, based on the reliable and valid data, the weights of factors were determined within the rating system. In this study, factors are compared to determine how important they are to the decision makers, with respect to the goal.

By changing the problem into a hierarchy of sub-problems, the AHP helps the decision makers to evaluate the decision elements by comparing them to one another using pairwise comparison. A numerical weight or priority is derived for each element of the hierarchy. The adoption of the AHP method in this study leads to generating the matrixes for assessing factors. Rather than prescribing a "correct" decision, the AHP helps the decision makers find the one that best suits their needs and their understanding of the problem. 


\section{Results and Discussion}

What the NZ prefabricated housing industry can learn from the other countries is customer focus, marketing investment, show-home and dedicated magazines. Also, architect collaborations with established housing manufacturers, widespread education about prefabrication through design competitions, university-led courses and exhibitions.

The New Zealand prefabricated housing industry can learn from the strategy of using a flexible construction system to provide an infinite range of housing configurations, collaborations with wellknown architects, offering a range of styles to broaden their marketing base and forming a marketing relationship with an established magazine brand to develop housing products for identified target consumer places. In addition, specific goals can be measured and tracked over time, and hence, timber prefab system can be managed and improved.

The main contribution of this study is to apply the AHP method to rate enablers and the prefab systems sustainability. The primary data was gained from semi-structured interviews with 10 construction practitioners who have had key involvement in the development of prefabricated building system in New Zealand. The outcomes are presented in Table 1.

\begin{tabular}{|c|c|}
\hline $\begin{array}{l}\text { New Zealand's barriers in timber prefab } \\
\text { system }\end{array}$ & \\
\hline $\begin{array}{l}\text { Susceptibility of timber to moisture, even in } \\
\text { treated conditions } \\
\text { Susceptibility of timber to fire, even in treated } \\
\text { conditions } \\
\text { Perceptions around the legacy of leaky } \\
\text { building issues in the industry } \\
\text { Durability issues compared to other materials } \\
\text { Structural integrity issues when exposed to } \\
\text { adverse weather conditions (e.g. warping, } \\
\text { twisting, shrinking, deflections }\end{array}$ & $\begin{array}{l}\text { Abundance of timber resource in New Zealand } \\
\text { Environmental sustainability properties of timber } \\
\text { use } \\
\text { Resistance to earthquake due to its lightness } \\
\text { NZ's familiarity with timber technology } \\
\text { Economy in the short term (long term economy in } \\
\text { question) } \\
\text { Advances in structural/engineered timber } \\
\text { technology (LVL, Glulam, SG) } \\
\text { Advances in more environmentally friendly } \\
\text { treatments to timber }\end{array}$ \\
\hline
\end{tabular}

Table 1: The result of data analysis from 10 semi-structured interviews

The AHP method was then applied twice to rank and analyze the complex questionnaire data and the rating systems of the barriers and the sustainability of the prefab methods. Therefore, two questionnaires have been developed and distributed among the experts, including the engineers, contractors, consultants and employer parties.

Figure 1 reveals that the Advances in structural timber technology is the most important factor in enablers with $22.5 \%$. In addition, Resistance to earthquake and Economy in short term are the second important factor with $16.2 \%$ and $16.0 \%$, respectively. Moreover, Environmental Sustainability and Advance in more environmentally friendly with $12 \%$ have the same weights in the enablers of the timber prefab system in New Zealand. 


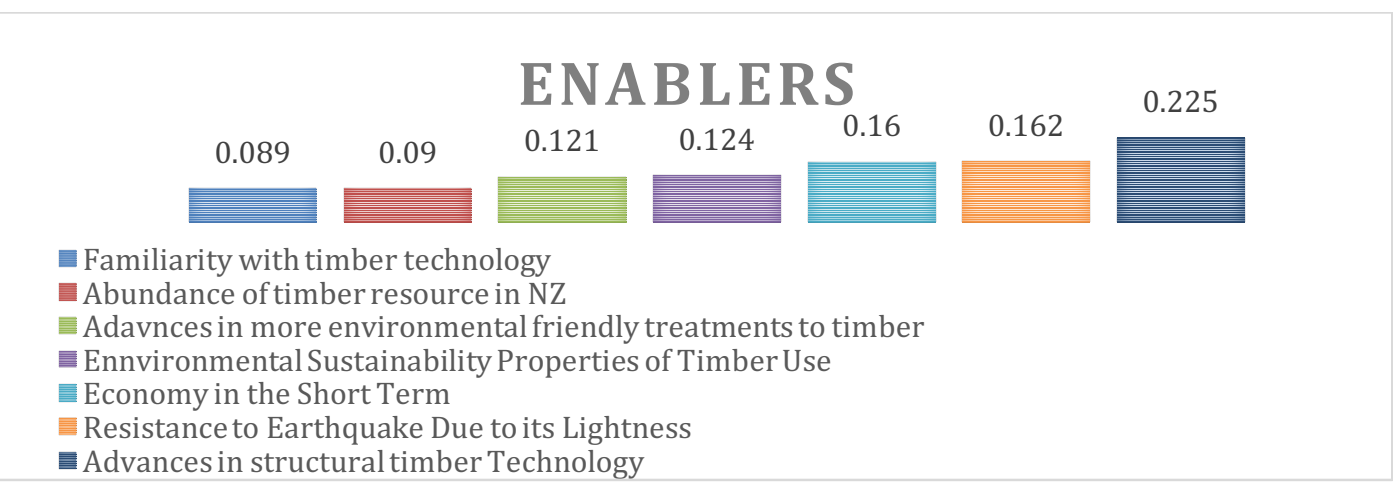

Figure 1: Influencing the enablers in improving wider uptake of the system as preferred choice in the NZ housing construction

Figure 2 illustrates the weight of sustainability in five different prefab systems. Therefore, Modular and Whole house system have the most influences on NZ's sustainability with $35 \%$ and $30.2 \%$, respectively. Although, Hybrid system has $20.6 \%$ influence, Panelized and Stick and Framing have the least important factors with $9.5 \%$ and $4.7 \%$.

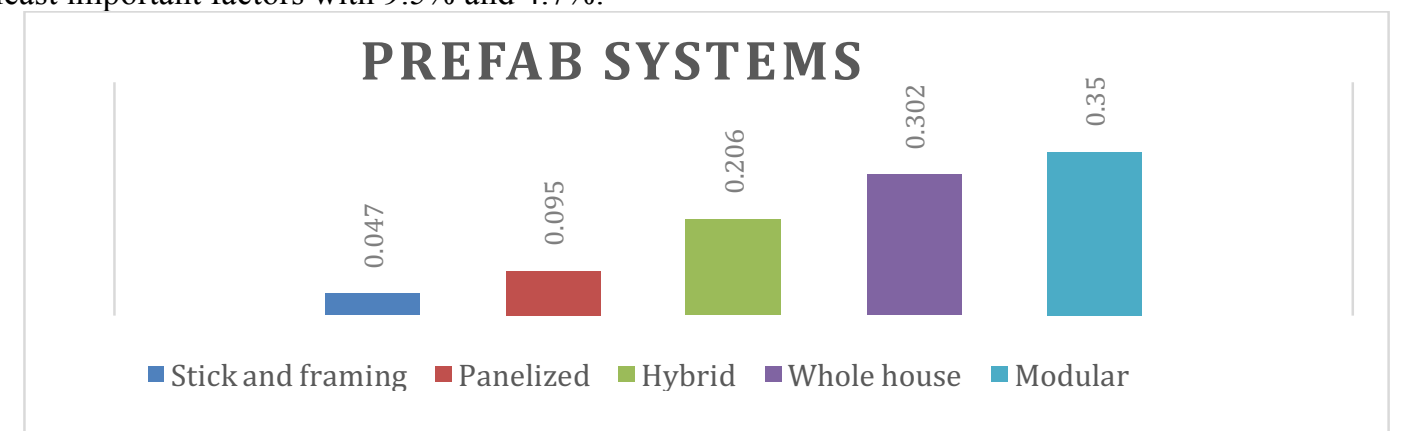

Figure 2: Prefab systems and their influence on NZ's sustainability

\section{Conclusions}

The study included both qualitative and quantitative aspects to contribute to the research with indepth literature, interviews and surveys to determine and assessment of enablers and barriers faced by New Zealand's prefabricated housing system with respect to their sustainability. As prefabrication is an important method to address issues of housing affordability, this study reveals that the timber modular housing system with respect to advances in their structural technology is the most sustainable timber method in the New Zealand within the acceptable risks and productivity. Although, Stick and Framing systems are the least sustainable prefab system. The research method can be generalized for other countries, enablers and types of prefab systems.

\section{References}


BELL, P. 2009. Kiwi Prefab: Prefabricated Housing in New Zealand: An Historical and Contemporary Overview with Recommendations for the Future. PhD Thesis.

BUCHANAN, A., DEAM, B., FRAGIACOMO, M., PAMPANIN, S. \& PALERMO, A. 2008. Multistorey prestressed timber buildings in New Zealand. Structural Engineering International, 18, 166-173.

BUCKETT, N., MARSTON, N., SAVILLE-SMITH, K., JOWETT, J. \& JONES, M. 2007. STUDY REPORT.

BURGESS, J., BUCKETT, N. \& PAGE, I. 2013. Prefabrication impacts in the New Zealand construction industry. BRANZ study report 279.

BUSINESS, M. O. 2013. Ministry of Business, Innovation and Employment [Online]. [Accessed].

CIMC. 2017. Modular Building Systems [Online]. [Accessed].

DIONISIO, M. R., KINGHAM, S., BANWELL, K. \& NEVILLE, J. 2016. The potential of geospatial tools for enhancing community engagement in the post-disaster reconstruction of Christchurch, New Zealand. Sustainable Cities and Society.

EDE, A. N., ADEBAYO, S. O., BAMIGBOYE, G. \& OGUNDEJI, J. 2015. Structural, economic and environmental study of concrete and timber as structural members for residential buildings in Nigeria. The International Journal of Engineering and Science (IJES), 4, 76-84.

HOWDEN-CHAPMAN, P. 2015. Home Truths: Confronting New Zealand's Housing Crisis, Bridget Williams Books.

LAWSON, R. \& OGDEN, R. Sustainability and process benefits of modular construction. TG57Special Track 18th CIB World Building Congress May 2010 Salford, United Kingdom, 2010. 38.

MAH, D. 2011. Framework for rating the sustainability of the residential construction practice. University of Alberta.

MAO, C., SHEN, Q., SHEN, L. \& TANG, L. 2013. Comparative study of greenhouse gas emissions between off-site prefabrication and conventional construction methods: two case studies of residential projects. Energy and Buildings, 66, 165-176.

MOHAMMAD, M. F. 2013. Construction environment: adopting IBS construction approach towards achieving sustainable development. Procedia-Social and Behavioral Sciences, 85, 8-15.

MOHD NAWI, M. N., LEE, A. \& MOHD NOR, K. 2011. Barriers to implementation of the industrialised building system (IBS) in Malaysia. The Built \& Human Environment Review.

NADIM, W. \& GOULDING, J. S. 2010. Offsite production in the UK: the way forward? A UK construction industry perspective. Construction innovation, 10, 181-202.

PAGE, I. New Zealand new housing characteristics and costs. S. Kajewski, K. Manley, \& K. Hampson (Chair), Queensland University of Technology, Australia. Symposium conducted at the meeting of the 19th CIB World Building Congress: Construction and Society, Brisbane, Australia, 2013.

QUICKSTATS, C. 2013. 2013 Census QuickStats about a place:

Auckland Region [Online]. [Accessed 2017].

SAATY, T. L. 1980. The Analytic (Hierarchy) Process, New York, St. Louis ua.

SHEN, L.-Y., TAM, V. W. Y., TAM, L. \& JI, Y.-B. 2010. Project feasibility study: the key to successful implementation of sustainable and socially responsible construction management practice. Journal of Cleaner Production, 18, 254-259.

SMITH, R. E. 2011. Prefab architecture: A guide to modular design and construction, John Wiley \& Sons.

STOCCHERO, A., SEADON, J. K., FALSHAW, R. \& EDWARDS, M. 2017. Urban Equilibrium for sustainable cities and the contribution of timber buildings to balance urban carbon emissions: A New Zealand case study. Journal of Cleaner Production, 143, 1001-1010.

TE ROOPU TAURIMA, O. 2016. Development and Efficiency of Prefabricated Building Components. Work, 10. 
UMAIR, S. M., NUMADA, M., AMIN, M. N. \& MEGURO, K. 2015. Fiber reinforced polymer and polypropylene composite retrofitting technique for masonry structures. Polymers, 7, 963-984.

WOOD, C. 2008. Sustainable Government Building(s). Property Institute, Wellington.

ZHANG, G. \& ZOU, P. X. 2007. Fuzzy analytical hierarchy process risk assessment approach for joint venture construction projects in China. Journal of Construction Engineering and Management, $133,771-779$. 